Tropical Journal of Pharmaceutical Research January 2017; 16 (1): 231-237

ISSN: $1596-5996$ (print); 1596-9827 (electronic)

(c) Pharmacotherapy Group, Faculty of Pharmacy, University of Benin, Benin City, 300001 Nigeria.

All rights reserved.

Available online at http://www.tjpr.org

Original Research Article

http://dx.doi.org/10.4314/tjpr.v16i1.31

\title{
Evaluation of the causes and cost impact of returned intravenous medications at a tertiary care hospital in Riyadh, Saudi Arabia
}

\begin{abstract}
Hamza AlSamanhodi ${ }^{1}$, Meshary Almeshary ${ }^{1}$, Kwame Amoh ${ }^{1,2}$, Saleh Aldekhael $^{1,2}$, Abdulmalik Alkatheri ${ }^{1,2}$, Shmeylan Alharbi ${ }^{1,2}$, Maha AlAmmari ${ }^{1}$, Salah AbuRuz ${ }^{2,3}$ and Abdulkareem Albekairy ${ }^{1,2^{\star}}$

${ }^{1}$ Pharmaceutical Care Services, King Abdulaziz Medical City, ${ }^{2}$ Pharmacy Practice Department, College of Pharmacy, King Saud Bin Abdulaziz University for Health Sciences,, Riyadh, Saudi Arabia, ${ }^{3}$ College of Pharmacy, University of Jordan, Amman, Jordan
\end{abstract}

*For correspondence: Email: bekairya@ngha.med.sa

Received: 12 August 2016

Revised accepted: 6 December 2016

\begin{abstract}
Purpose: To evaluate the main reasons for returning intravenous (IV) medications and to determine its cost impact in an in-patient setting in a Saudi tertiary care hospital.

Methods: The study was conducted over a one-month period at the central IV room of the in-patient pharmacy unit at King Abdulaziz Medical City (KAMC), Riyadh, Saudi Arabia. All returned IV medications were evaluated in terms of frequency, causes and cost.

Results: The total number of IV medications returned was 2,061 items. The most common reasons for returning IV medications were drug discontinuation (933 items, $45.3 \%$ ), dispensing of an extra quantity (396 items, $19.2 \%$ ), patient deaths (173 items, $8.4 \%$ ), dose changes (171 items, $8.3 \%$ ) and drugs being held (150 items, $7.3 \%)$. The total cost of all the returned IV medications was US\$26,805.80), which accounts for $(13.65 \%)$ of the total pharmacy's budget. Wasted medication cost was US $\$ 13,877.80$ ) which constitute $51.77 \%$ of returned medication cost.

Conclusions: The results of this study indicate that IV medication wastage is a serious problem with significant cost impact, with drug discontinuation and dispensing of an extra quantity of medication being the two main reasons for returning IV medications. Effective communication among health care professionals, pharmacist training, and adherence to standard practice guidelines might be the most vital strategies to reduce medication wastage.
\end{abstract}

Keywords: Medication wastage, In-patient, Cost impact, Intravenous medications, Tertiary care

Tropical Journal of Pharmaceutical Research is indexed by Science Citation Index (SciSearch), Scopus, International Pharmaceutical Abstract, Chemical Abstracts, Embase, Index Copernicus, EBSCO, African Index Medicus, JournalSeek, Journal Citation Reports/Science Edition, Directory of Open Access Journals (DOAJ), African Journal Online, Bioline International, Open-J-Gate and Pharmacy Abstracts

\section{INTRODUCTION}

Medications wastage is a major issue facing all health care systems worldwide. It imposes a significant financial burden on the pharmacy's budget, not only because of the cost of items being returned but also due to the wasted time and the cost of disposing of wasted medications [1]. Medications wastage contributes a large proportion of the ballooning health care cost worldwide. In the United States, for example, the estimated cost of wasted medications is more than $\$ 1$ billion yearly $[2,3]$. The financial value of medications that are not used or wasted in the United Kingdom is estimated to reach up to $£$ 300 million annually [4]. In Canada, medications wastage has been cited as one of the most critical factors for the increasing consumption of 
pharmaceutical products and rising health care cost, which has been estimated to be approximately $\$ 8$ billion per year [5].

Practically, medications wastage cannot be completely eliminated. However, carefully examining contributing factors and identifying the most common and expensive medications involved, is certainly worthwhile, and may help in recognizing the most suitable measures to reduce medication wastage [6].

Many studies have been conducted to address medications wastage issue [3,4,6-13]. However, the majority of these studies were carried out in outpatient setting $[3,4,6,7,9-11,13]$. Not much is documented on investigating the causes and cost impact of medications wastage in the inpatient setting $[8,12]$. Similarly, in Saudi Arabia, few studies on medication wastage have been conducted in the outpatient setting [14] and only one study in inpatient setting [8]. This study was conducted at a tertiary university teaching hospital in Riyadh. The data were collected in the inpatient pharmacy over a period of one month. One thousand two hundred and eighteen medications were dispensed, out of which 265 $(21.75 \%)$ medications were returned to the inpatient pharmacy. The major reasons for returning the medications were: medication discontinuation, switching from IV therapy to oral, patient discharge, extra dose delivery, refill order and patient death. The total cost of wasted IV medications was estimated to be around 28,800 SAR per month $(\$ 7679.1)$ [8].

The aims of this study were to investigate the main reasons for returning IV medications and to calculate its cost impact in an inpatient setting. The findings will be used to help developing strategies to minimize medications wastage.

\section{METHODS}

\section{Study design and setting}

The study was a cross-sectional, observational study performed over a period of one month at the central IV room of the inpatient pharmacy at King Abdulaziz Medical City (KAMC). KAMC is a 1025 bed tertiary care hospital in Riyadh, Saudi Arabia.

The inpatient pharmacy is a part of the pharmaceutical care services department at KAMC. It provides 24 hours services covering all admitted patients. During the day shift, pharmaceutical services are provided through a decentralized system (satellite pharmacies) and during the evening and night shifts through centralized pharmacy system with limited satellite pharmacy services.

The study was approved by the Institutional Review Board (IRB) of King Abdullah International Medical Research Center (KAIMRC) prior to commencement of the study.

\section{Data collection}

During the study period and on a daily basis, the returned IV medications were collected in the IV room fridge. Data collection sheet was developed to collect all pertinent information including: medication name, dose, quantity, type of IV preparation (IV piggyback, IV syringes or IV large volume), reason for returning, recycling status, therapeutic/pharmacological classification, and unit cost of the medication.

Depending on the stability of the IV preparation and whether or not the returned amount can be used again, the returned items were categorized into recyclable and non-recyclable preparations. All returned non-recyclable items were defined as "wastage". The reasons for returning the IV preparations were obtained by using the pharmacy computer system and through contacting the responsible nurse/pharmacist when necessary.

The total cost of all the returned items was calculated using the unit prices provided by the Logistics and Contracts Management Department at the KAMC.

\section{Data analysis}

Data were extracted from data collection sheets and entered into Microsoft Excelß (2010). All of the data in this study were categorical and were expressed as frequency and percentages.

\section{RESULTS}

\section{Frequency and cost of returned medications}

During the study period, a total of 2,061 items were returned to the main pharmacy. Details for returned medications were complete for 1,965 $(95.34 \%)$ items. Of these, 627 items (30.42\%) were recyclable while 1,434 items $(69.57 \%)$ were non-recyclable and therefore wasted. The total cost of returned medications during the study period was US $\$ 26,805.80)$. This amount accounted for $13.65 \%$ of the pharmacy department's budget for the IV room at the hospital. Of this amount, non-recyclable items worth US $\$ 13,877.80$ ) and constitute $51.77 \%$ of returned medications cost. 
The frequencies of returned medications for adults and paediatrics sections are summarized in Table 1. Most of the returned medications were from the adults' section (70.6\%).

Table 1: Distribution frequency of returned medications in adult and paediatric sections

\begin{tabular}{lccc}
\hline $\begin{array}{l}\text { Hospital } \\
\text { section }\end{array}$ & ICU & Non-ICU & Total \\
\hline Paediatric & 377 & 229 & 606 \\
& $(18.29 \%)$ & $(11.11 \%)$ & $(29.4 \%)$ \\
Adult & 480 & 975 & 1455 \\
& $(23.29 \%)$ & $(47.3 \%)$ & $(70.6 \%)$ \\
Total & $\mathbf{8 5 7}$ & $\mathbf{1 2 0 4}$ & $\mathbf{2 0 6 1}$ \\
& $\mathbf{( 4 1 . 5 8 \% )}$ & $\mathbf{( 5 8 . 4 2 \% )}$ & \\
\hline
\end{tabular}

The unit with the most frequently returned items in the paedatrics' section was the paediatric cardiac intensive care unit (229 items, $11.11 \%$ ), followed by the general paediatric intensive care unit (106 items, $5.14 \%$ ). The unit with the most frequently returned items in the adults' section was the medical intensive care unit (95 items, 4.6 $\%)$.

\section{Most frequently returned medications}

The most frequently returned classes of medications with their respective cost are summarized in Table 2. The most frequent class of returned IV medications was antibiotics with 971 items $(47.11 \%)$ and had a financial value of $28.38 \%$ of the total returned items cost, while electrolyte replacement preparations were the second most frequent (356 items,17.27\%) and had a financial value of $2.24 \%$ of the total cost. Gastrointestinal drugs were the third most frequent (135 items, $6.55 \%$ ) and accounted for $2.38 \%$ of the total cost. Analgesics and antipyretics were the fourth most frequent $(107$ items, $5.19 \%$ ) with a financial value of $0.75 \%$ of the total cost. Blood derivatives were the fifth most frequent with (93 returned items, $4.51 \%$ ) and accounted for $16.83 \%$ of the total cost.

The most frequently returned specific medications with their respective cost are summarized in Tables 3. Potassium chloride was the most frequently returned medication. Three of the top five returned medications were antibiotics.

\section{Reasons for returning medications}

Figure 1 illustrates the most common reasons for returning IV medications. The most common reasons for returning IV medications were medication discontinuation (933 items, $45.30 \%$ ), dispensing of an extra quantity (396 items, 19.20 $\%)$, patient deaths (173 items, $8.4 \%$ ), dose changes (171 items, $8.3 \%$ ) and medication being held (150 items, $7.3 \%$ ). In the majority of classes, items were most frequently returned as a result of medication discontinuation except for analgesics and antipyretics which had the highest return rate due to dispensing of an extra quantity (Table 2).

\section{DISCUSSION}

The results of this study indicated that antibiotics are the most frequently returned class of medications. This finding is consistent with other published studies [8,12]. Gastrointestinal drugs, electrolyte replacement preparations, analgesics, and antipyretics were also among the top five classes of returned medications. The units with the most returned items were the paediatric intensive care unit and the adult medical intensive care unit where these medications are frequently used. To reduce wastage; therefore, rational drug use should be emphasized in these units.

The most common reason for returning intravenous medications was discontinuation of medications per physician order. Similar findings were reported in previous studies [8]. One of the main factors that may explain this finding is the lack of adherence to international guidelines regarding the use of medications, antibiotics in particular. According to a recent study, nearly a third of antibiotics prescribed in the United States are unnecessary [15].

Physicians tend to prescribe expensive potent IV antibiotics for clinical conditions that do not require them, refuse to switch to the much cheaper oral alternatives per guideline recommendations, and misdiagnose viral infections as bacterial causes resulting in the indiscriminate use of antibiotics. In the majority of cases, antibiotics were initiated, then discontinued upon negative results of septic workup and clinical improvement of patients.

Dispensing of an extra quantity of medications was the second most common reason for IV medications being returned to the main pharmacy. This can be remedied by training and directing staff pharmacists to be extra vigilant through meticulous checking to ensure that the appropriate amount of prescribed medication is dispensed.

Medications dose changes were also a common reason for intravenous medications being returned to the main pharmacy. Very little, if anything, can be done to change the need for 
Table 2: Number of returned items for top 5 classes of medications, the reasons for returning them and their respective cost

\begin{tabular}{|c|c|c|c|c|c|c|c|c|c|c|}
\hline \multirow[b]{2}{*}{ Class } & \multirow[b]{2}{*}{$\begin{array}{c}\text { Frequen } \\
\text { cy } \\
(\%)\end{array}$} & \multicolumn{8}{|c|}{ Reasons for returning } & \multirow{2}{*}{$\begin{array}{l}\text { Cost } \\
\text { (US\$) }\end{array}$} \\
\hline & & $\begin{array}{c}\text { Dose } \\
\text { changed }\end{array}$ & $\begin{array}{c}\text { Medicatio } \\
n \\
\text { Discontin } \\
\text { ued }\end{array}$ & $\begin{array}{c}\text { Patient } \\
\text { Discharge } \\
\text { d }\end{array}$ & $\begin{array}{l}\text { Patients' } \\
\text { deaths }\end{array}$ & $\begin{array}{c}\text { Extra } \\
\text { dose } \\
\text { dispens } \\
\text { ed }\end{array}$ & $\begin{array}{c}\text { Medicatio } \\
\mathrm{n} \text { held }\end{array}$ & $\begin{array}{l}\text { Patient } \\
\text { transferr } \\
\text { ed }\end{array}$ & $\begin{array}{l}\text { Other } \\
\text { reasons }\end{array}$ & \\
\hline Antibiotics & $\begin{array}{c}971 \\
(47.11 \%)\end{array}$ & $\begin{array}{c}97 \\
(9.99 \%)\end{array}$ & $\begin{array}{c}500 \\
(51.49 \%)\end{array}$ & $\begin{array}{c}60 \\
(6.18 \%)\end{array}$ & $\begin{array}{c}77 \\
(7.93 \%)\end{array}$ & $\begin{array}{c}174 \\
(17.92 \%)\end{array}$ & $\begin{array}{c}18 \\
(1.85 \%)\end{array}$ & $\begin{array}{c}9 \\
(0.93 \%)\end{array}$ & $\begin{array}{c}36 \\
(3.7 \%)\end{array}$ & $\begin{array}{c}7,607 \\
.12 .5 \\
3\end{array}$ \\
\hline $\begin{array}{l}\text { Electrolyte } \\
\text { Replacement } \\
\text { Preparations }\end{array}$ & $\begin{array}{c}356 \\
(17.27 \%)\end{array}$ & $\begin{array}{c}23 \\
(4.46 \%)\end{array}$ & $\begin{array}{c}113 \\
(31.74 \%)\end{array}$ & $\begin{array}{c}8 \\
(2.25 \%)\end{array}$ & $\begin{array}{c}8 \\
(2.25 \%)\end{array}$ & $\begin{array}{c}99 \\
(27.8 \%)\end{array}$ & $\begin{array}{c}80 \\
(22.47 \%)\end{array}$ & $\begin{array}{c}6 \\
(1.69 \%)\end{array}$ & $\begin{array}{c}19 \\
(5.34 \%)\end{array}$ & $\begin{array}{c}600.5 \\
3\end{array}$ \\
\hline $\begin{array}{l}\text { Gastrointestinal } \\
\text { Drugs }\end{array}$ & $\begin{array}{c}135 \\
(6.55 \%)\end{array}$ & $\begin{array}{c}26 \\
(19.26 \%)\end{array}$ & $\begin{array}{c}41 \\
(30.37 \%)\end{array}$ & $\begin{array}{c}23 \\
(17.04 \%)\end{array}$ & $\begin{array}{c}17 \\
(12.59 \%)\end{array}$ & $\begin{array}{c}21 \\
(15.56 \%)\end{array}$ & $\begin{array}{c}2 \\
(1.48 \%)\end{array}$ & 0 & $\begin{array}{c}5 \\
(3.7 \%)\end{array}$ & $\begin{array}{c}637.3 \\
3\end{array}$ \\
\hline $\begin{array}{l}\text { Analgesics and } \\
\text { Antipyretics }\end{array}$ & $\begin{array}{c}107 \\
(5.19 \%)\end{array}$ & $\begin{array}{c}8 \\
(7.48 \%)\end{array}$ & $\begin{array}{c}34 \\
(31.78 \%)\end{array}$ & $\begin{array}{c}13 \\
(12.15 \%)\end{array}$ & $\begin{array}{c}1 \\
(0.93 \%)\end{array}$ & $\begin{array}{c}40 \\
(37.38 \%)\end{array}$ & $\begin{array}{c}7 \\
(6.54 \%)\end{array}$ & 0 & $\begin{array}{c}4 \\
(3.74 \%)\end{array}$ & $\begin{array}{c}199.7 \\
3\end{array}$ \\
\hline Blood derivatives & $\begin{array}{c}93 \\
(4.51 \%)\end{array}$ & 0 & $\begin{array}{c}54 \\
(58.06 \%)\end{array}$ & $\begin{array}{c}5 \\
(5.38 \%)\end{array}$ & $\begin{array}{c}10 \\
(10.75 \%)\end{array}$ & $\begin{array}{c}15 \\
(16.13 \%)\end{array}$ & $\begin{array}{c}1 \\
(1.08 \%)\end{array}$ & $\begin{array}{c}5 \\
(5.38 \%)\end{array}$ & $\begin{array}{c}3 \\
(3.23 \%)\end{array}$ & $\begin{array}{c}4512 . \\
8\end{array}$ \\
\hline
\end{tabular}

Note: Exchange rate of SAR3.75 to US $\$ 1.00$ used for converting costs in Saudi riyal to US dollar

Table 3: Top five returned medications and their respective cost

\begin{tabular}{lll}
\hline Medication & Frequency & Cost (US\$) \\
\hline Potassium chloride & $170(8.25 \%)$ & $32.80(0.12 \%)$ \\
Vancomycin & $161(7.81 \%)$ & $870.96(3.25 \%)$ \\
Metronidazole & $127(6.16 \%)$ & $71.12(0.26 \%)$ \\
Tazocin & $115(5.58 \%)$ & $1035.0(3.86 \%)$ \\
Acetaminophen & $107(5.19 \%)$ & $199.73(0.75 \%)$ \\
\hline
\end{tabular}

Note: Exchange rate of SAR3.75 to US $\$ 1.00$ used for converting costs in Saudi riyal to US dollar 


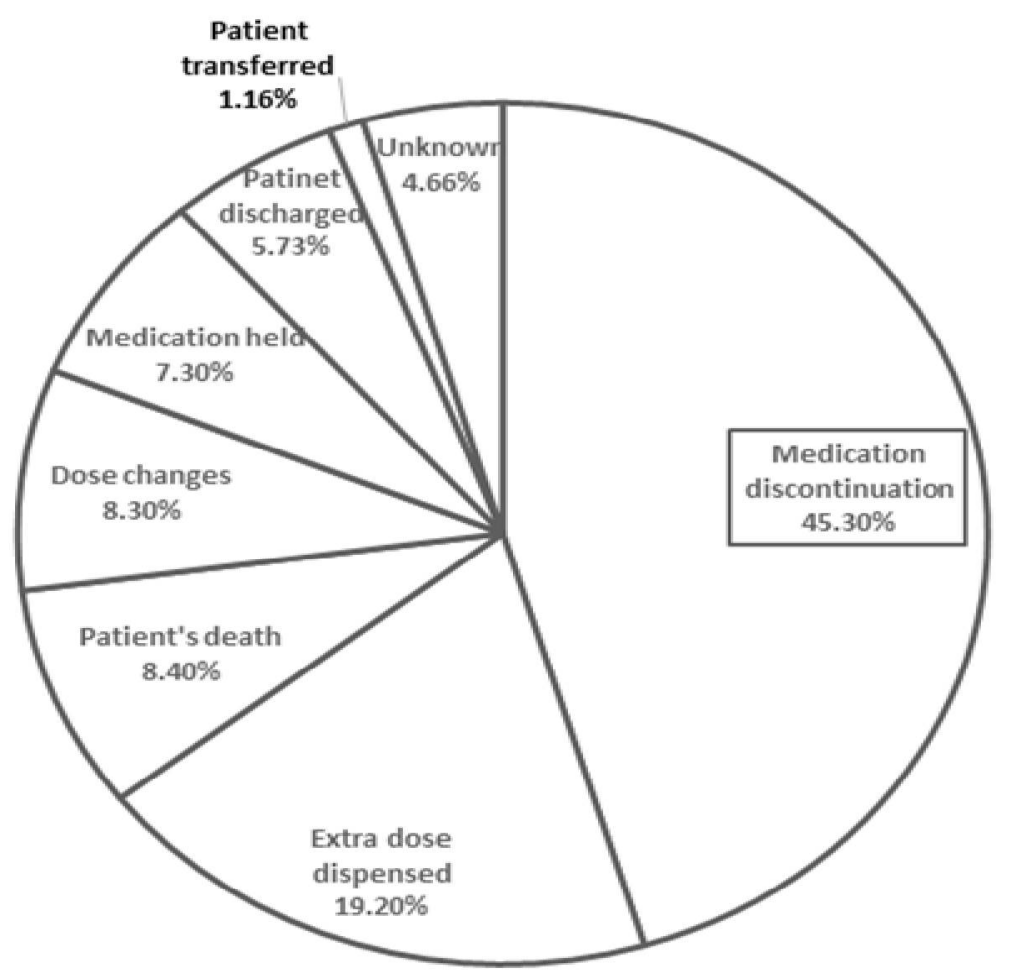

Figure 1: Reasons for returning IV medications

medication dosage adjustments when necessary because of either hepatic or renal impairment.

The best way to reduce intravenous medications being returned to the main pharmacy, as a result of medications being held and never resumed, would be for staff pharmacists to ensure that the unit-dose drug distribution system is strictly adhered to. Using this approach, only a small quantity would be wasted, if a medication is held and never resumed. The use of unit-dose drug distribution system has also been found to reduce medication errors substantially [16].

Early discharge of patients was also a common reason for returning IV medications. Encouraging physicians to plan the discharge of their patients about two to three days ahead of time and switching to oral medications as soon as feasible would be helpful in reducing wastage of medications. The discharge planning process, when conducted early, has been shown to improve patients' care and the cost-effective use of resources [17].

It was evident from the results that more than half of the returned medications were wasted because of non-recyclability. Inability to recycle has been found to be the result of two major factors namely, short stability of IV preparations and using unstandardized doses. Implementing dosing standardization and polices that guide the medication use process in the hospital setting have also been found to be important in minimizing medication errors and promoting medication safety and control [18].

The study results indicate clearly that the current strategies in dealing with IV medications are not effective in reducing the wastage of medications and therefore there is an urgent need to implement new strategies. Lack of effective communication among different health care providers who are involved in the medication use process plays a major role and should be the focus of these strategies. Improving communication among health care providers will lead to vast improvement in health care including reducing the amount of returned IV medications and consequently, reduce the wastage and render the pharmacy staff more productive [19].

A recent study has also evaluated the impact of increasing the use of premixed IV solutions and increased IV production frequency on IV wastages [20]. Using these strategies, the number of wasted IV doses has been reduced from $2673(6.14 \%)$ to $675(1.69 \%)$ per month.

Finally, it should be noted that the total cost of the returned intravenous medications quoted in this study is the cost of the wasted medications alone. Thus, if other ancillary costs such as cost of wasted bottles or piggybacks, large volume 
bags, wasted efforts and time of pharmacists and pharmacy technicians are considered, the cumulative cost would certainly be enormous.

\section{Limitations of the study}

There are several limitations to this study. These limitations include: short duration, single center, not including the ancillary cost of the medications, and the lack of a structured investigation into the factors behind returning IV medications.

\section{CONCLUSION}

IV medications wastage is a serious problem in the inpatient setting and has a significant cost impact. This study has highlighted that drug discontinuation and dispensing of an extra quantity of medications were the two main reasons for returning IV medications. Current strategies in dealing with returned IV medications are not effective in reducing the wastage of medications and therefore there is an urgent need to implement new strategies. Effective communication between health care professionals, pharmacists training, and adherence to standard practice guidelines especially with antibiotics could be the most vital strategies.

\section{DECLARATIONS}

\section{Conflict of Interest}

No conflict of interest associated with this work.

\section{Contribution of Authors}

The authors declare that this work was done by the authors named in this article and all liabilities pertaining to claims relating to the content of this article will be borne by them.

\section{Open Access}

This is an Open Access article that uses a funding model which does not charge readers or their institutions for access and distributed under the terms of the Creative Commons Attribution License (http://creativecommons.org/licenses/by 14.0) and the Budapest Open Access Initiative (http://www.budapestopenaccessinitiative.org/rea d), which permit unrestricted use, distribution, and reproduction in any medium, provided the original work is properly credited.

\section{REFERENCES}

1. Daughton CG. Cradle-to-cradle stewardship of drugs for minimizing their environmental disposition while promoting human health. I. Rationale for and avenues toward a green pharmacy. Environ Health Perspect 2003; 111: 757-774.

2. Bain KT. Public Health Implications of Household Pharmaceutical Waste in the United States. Health Serv Insights 2010; 3: 21-36.

3. Morgan TM. The Economic Impact of Wasted Prescription Medication in an Outpatient Population of Older Adults. J Fam Pract 2001; 50: 779-781.

4. Mackridge AJ, Marriott JF. Returned medicines: waste or a wasted opportunity? J Public Health 2007; 29: 258262.

5. Tchen J, Vaillancourt $R$, Pouliot $A$. Wasted medications, wasted resource. Can Pharm J 2013; 146: 181-182.

6. Braund $R$, Chuah $F$, Gilbert R, Gn G, Soh A, Tan $L Y$, Tiong HS, Yuen $Y$-C. Identification of the reasons for medication returns. N Z Fam Physician 2008; 35: 248252.

7. Abahussain EA, Ball DE, Matowe WC. Practice and Opinion towards Disposal of Unused Medication in Kuwait. Med Princ Pract 2006; 15: 352-357.

8. Al-Dhawailie AA. Control of intravenous medication wastage at a teaching hospital in Saudi Arabia. Saudi Med J 2011; 32: 62-65.

9. Coma A, Modamio P, Lastra C, Bouvy M, Mariño E. Returned medicines in community pharmacies of Barcelona, Spain. Pharm World Sci 2008; 30: 272-277.

10. Ibrahim SZ, Mamdouh HM, El-Haddad IZ. Analysis of medications returned to community pharmacies in Alexandria, Egypt. Life Sci J 2012; 9: 746-751.

11. James T, Helms M, Braund R. Analysis of medications returned to community pharmacies. Ann Pharmacother 2009; 43: 1631-1635.

12. Kagashe GA, Makenya FB, Buma D. Medicines Wastage at a Tertiary Hospital in Dar Es Salaam Tanzania. J App Pharm Sci 2014; 4: 98-102.

13. West L, Diack L, Cordina M, Stewart D. A systematic review of the literature on 'medication wastage': an exploration of causative factors and effect of interventions. Int J Clin Pharm 2014; 36: 873-881.

14. Abou-Auda HS. An economic assessment of the extent of medication use and wastage among families in Saudi Arabia and Arabian Gulf countries. Clin Ther 2003; 25: 1276-1292.

15. Fleming-Dutra KE, Hersh AL, Shapiro DJ, Bartoces $M$, Enns EA, File TM, Jr., Finkelstein JA, Gerber JS, Hyun $D Y$, Linder JA, et al. Prevalence of Inappropriate Antibiotic Prescriptions Among US Ambulatory Care Visits, 2010-2011. JAMA 2016; 315: 1864-1873.

16. Fontan JE, Maneglier V, Nguyen VX, Loirat C, Brion $F$. Medication errors in hospitals: computerized unit dose drug dispensing system versus ward stock distribution system. Pharm World Sci 2003; 25: 112-117. 
17. Ohta B, Mola A, Rosenfeld P, Ford S. Early Discharge Planning and Improved Care Transitions: Pre-Admission Assessment for Readmission Risk in an Elective Orthopedic and Cardiovascular Surgical Population. Int J Integr Care 2016; 16: 10.

18. Aseeri MA. The impact of a pediatric antibiotic standard dosing table on dosing errors. J Pediatr Pharmacol Ther 2013; 18: 220-226.
19. Boomer G, Savoy LB, Marten R. The effect of oral communication on intravenous wastage: talk is cheap. Hosp Pharm 1993; 28: 404-405, 407-409.

20. Lin AC, Penm J, Ivey MF, Deng Y, Commins M. Applying Lean Techniques to Reduce Intravenous Waste Through Premixed Solutions and Increasing Production Frequency. J Healthc Qual 2016; Epub ahead of print. 